This item was submitted to Loughborough's Research Repository by the author.

Items in Figshare are protected by copyright, with all rights reserved, unless otherwise indicated.

\title{
Autonomous vehicles in developing countries: a case study on user's view point in Pakistan
}

PLEASE CITE THE PUBLISHED VERSION

http://dx.doi.org/10.1007/978-3-319-41682-3

\section{PUBLISHER}

C Springer International Publishing

\section{VERSION}

AM (Accepted Manuscript)

\section{PUBLISHER STATEMENT}

This work is made available according to the conditions of the Creative Commons Attribution-NonCommercialNoDerivatives 4.0 International (CC BY-NC-ND 4.0) licence. Full details of this licence are available at: https://creativecommons.org/licenses/by-nc-nd/4.0/

\section{LICENCE}

CC BY-NC-ND 4.0

\section{REPOSITORY RECORD}

Sanaullah, Irum, Amjad Hussain, Amna Chaudhry, Keith Case, and Marcus P. Enoch. 2019. "Autonomous Vehicles in Developing Countries: A Case Study on User's View Point in Pakistan”. figshare. https://hdl.handle.net/2134/22212. 


\title{
Autonomous Vehicles in Developing Countries: A Case Study on user's view point in Pakistan
}

\author{
Irum Sanaullah ${ }^{1}$, Amjad Hussain ${ }^{2 *}$, Amna Chaudhry ${ }^{1}$, Keith Case ${ }^{3}$, \\ Marcus Enoch ${ }^{4}$ \\ 1,2 Department of Transportation Engineering and Management, and Department of Industri- \\ al and Manufacturing Engineering, University of Engineering and Technology, Lahore, \\ Pakistan. \\ ${ }^{3,4}$ Wolfson School of Mechanical and Manufacturing Engineering and Department of Civil \\ and Building Engineering, Loughborough University, UK \\ Irum.sanaullah@uet.edu.pk; chamjad@uet.edu.pk; aaminah.ch@gmail.com; \\ k.case@lboro.ac.uk; m.p.enoch@lboro.ac.uk
}

\begin{abstract}
Technological advancements are continuously changing the human life. Like many other developments, autonomous vehicle system is attracting public interest and being widely discussed by all the stakeholders. Recent reports show that in future, autonomous vehicles or self-driving cars will be on roads in developed countries such as in UK and US. In this age of information technology, advancements made in developed countries not only move to the developing countries but also impact the opinions and lives of the people living in these countries. Therefore, there is a need to develop more effective strategies which can help the adaption of upcoming technologies in transport systems like autonomous vehicles. In this respect, user's perception becomes highly significant as this can help designers by providing them the information about real time issues and human observations. Up till now, no significant work has been carried out on exploring the user's perception about autonomous vehicles in developing countries like Pakistan. This study aims at capturing the user's view point about the use of autonomous vehicles which can provide relevant information on perceived benefits and challenges in user's perspective. An underlying objective is also to compare this perspective with developed countries like US, UK, and Australia etc. Findings of the study will help in assessing user's perceptions in terms of challenges, the level of awareness and understanding about autonomous vehicles. It will lead to shaping up the strategies to address the needs of users so that more viable and equally acceptable technological interventions can be made.
\end{abstract}

Keywords: Autonomous vehicle · User's perception · Human driven vehicles

\footnotetext{
* Amjad Hussain

Department of Industrial and Manufacturing Engineering, University of Engineering and Technology, Lahore, 54890 Pakistan. chamjad@gmail.com
} 


\section{Introduction}

This paper explores user's perception about the use of autonomous or self-driving vehicles in Pakistan. The focus of the study is to analyze the factors of awareness, reliability, safety, convenience and comfort of the autonomous vehicle system in the user's point of view.

\section{Background Literature}

In the last century, automotive sector has made advancements to improve the cost, comfort and safety of vehicles [1]. Autonomous Transport system is one of these developments defined as the unmanned system, which provides self- directed and independent transfer of people and goods without human involvement. This system includes the controlling of driverless vehicles, movement of intelligent vehicles and independent navigation [2]. Autonomous vehicle is known as 'driverless car', which can plan and drive by itself by detecting the painted lines or a magnetic monorail implanted in the road. It is also named as autopilot or automated guided vehicle (AGV) [3].

The autonomous vehicle consists of Visual Guidance System (VGS), Vehicle Control System (VCS), Vehicle Piloting System (VPS) and Robust Communications System (RCS) [4]. Studies suggest that advantages of Autonomous Transport Systems include increase in road and parking capacity, improved safety, efficient traffic flow, and decrease in traffic congestion and fuel economy. Autonomous vehicles are small in size, which can travel on roads with the smaller gaps between them and can increase the road capacity up to 30\% [3], [5]. The capacity on highways can increase by 3 to 8 times, if the autonomous vehicles travel in platoons. It is also possible for vehicles to drive bumper to bumper at full speed if the spacing is eventually reduced with the perfect connected device [6]. Driverless cars can drop off the passengers and can park themselves far away where the space is available and can return when they are required to pick up the passengers. In this way an autonomous transportation system can eliminate the problem of parking scarcity [7]. As human error cause 90 percent of the traffic accidents, the use of autonomous vehicles can significantly reduce the number of crashes. Folsom (2011) carried out a comparison of accident rates of motor vehicles to those of autonomous vehicle (commuter rail) system in the city of Lille in France [8]. The study concluded that motor vehicles are 33 times as risky as autonomous trains on a reserved path. The Vancouver autonomous Sky Train System in Canada gave the same accident rate facts as the autonomous vehicle system in Lille gave in the comparison with Light Rail Transit (LRT) or Rapid Rail Transit (RRT) systems. The application of autonomous system can reduce the number of accidents due to its increased reliability and precision as compared to human drivers and therefore it is an effective solution for drunk driving. Also with the use of autonomous vehicles, the number of automated- related casualties can be decreased to halve $(1.2$ million) per year overall the world [2, 9].

In the start of autonomous system application, the autonomous vehicles will drive in combination with human driven vehicles. In this case autonomous vehicles will follow the traffic laws and human drivers will have the option to follow the laws or not. 
This can create the state of confusion and problem [7]. However with the fully autonomous system the vehicles will travel at design speed on the main line, and will only change the speed on exit or entry ramps. The vehicles in system will continue to drive at full speed if the system is saturated and new vehicles will not enter the system. The interchanges will be assisted by parking buffers to provide the space for merging while vehicle changes their routes [8]. The vehicles with consistent speed on roads will result in the efficient traffic flow and less traffic jams.

Drivers need gap between vehicles while driving for perception and reaction time to apply breaks in emergency situation. In autonomous vehicles, due to central computer control system the following vehicle will know about the leading vehicle that when it will decelerate, take turn and accelerate before it takes the action. The perception time will be few milliseconds and therefore it can decrease the safe following distance between vehicles. The computer- controlled vehicles would drive close together on highways due to the awareness and prompt response; hence traffic congestion can be reduced [8].

Wu et al. (2011)[10] carried out a study on fuel economy optimization system in human driven and autonomous vehicles. They concluded that the application of optimal model in autonomous vehicles will be more helpful to increase the fuel economy as compared to the human driven vehicles.

With all the advantages of autonomous vehicles mentioned above, there are perspective challenges and issues which need to be addressed.

Firstly it is necessary to make drivers to accept that car can have a drive independently. Naturally, it is difficult for a traditional driver to trust that car will apply the brakes when required in the case of accident. It might take years to convince the society to trust driverless car operating in rush hours traffic [10].

The social issues related to the autonomous system include:

Will people trust using driverless car?

Will policy makers allow the driverless cars on roads?

Who will be responsible for mishaps and accidents?

Will people have choice to drive by themselves when they want?

McCarthy (2009) [11] states "The very nature of autonomous systems raises social, legal and ethical issues. People tend to be more accepting of a technology if they can choose whether or not to adopt it and have some control over its use".

The autonomous system is essentially outside the user's control of users; hence people's perception of the system can be negative. Therefore there is possibility of excluding the people who don't want to the part of system. Autonomous systems are required sometimes where humans might make bad decision, and therefore human dominance can be problematic. It leads to the query whether autonomous systems will be trusted more than humans in some situations. The slow provision of new features such as automatic parking and adaptive cruise control can make it easier for people to accept the autonomous system gradually (Stock, n. d.). 
It is also important to convince the law makers to allow the autonomous cars on the road and to resolve issue of responsibility in the case of accidents.

DARPA urban challenge has proved that it is absolutely possible to imply fully autonomous cars to gain convenience, safety, and environmental benefits. However, the issues discussed above need to be solved by taking gradual steps to make people familiar with the system and gaining the acceptance by politicians and lawmakers.

\section{Design of Survey Questionnaire and the Targeted Respondents}

The survey questionnaire was prepared to get public opinion on the adaptation of self-driving vehicle technology in Pakistan. The factors that were considered for preparing the survey questionnaire included were mainly based on (i) Human Factors identified by the previous literature that impact the automation (ii) Roadway and Traffic Operational Factors such as safety and mobility.

The following factors mainly have been included for getting drivers' perception on the autonomous vehicle technology:

- Familiarity with the technology

- Interest

- Reliability

- Safety

- Stress

- Convenience

- Traffic Delays

- Roadway Safety

- Training Requirement

Additionally, questions were prepared for the drivers who have used some level of automation before such as Cruise Control System. This was done to get an idea on the differences in opinions/ perceptions that may exist between such users' and the other drivers.

In order to get more reasonable opinion on the aforementioned factors, mostly people from the technical background, holding either bachelor's degree or above, were targeted. People from non-technical background were also included in the sample for conducting the survey to get an idea on the differences in the perceptions. Different age groups of both male and female survey participants, that were considered, included: 20-30 years, 31-40 years, and more than 40 years as shown in the Table 1.

Table 1. Demographics for 99 respondents

\begin{tabular}{cc}
\hline Demographics & Percent \\
\hline
\end{tabular}




\begin{tabular}{lll}
\hline Gender & Male & 75.8 \\
& Female & 24.2 \\
Age & 20-30 years & 56.6 \\
& 30-40 years & 27.3 \\
& $>40$ years & 12.1 \\
Qualification & Graduate Technical & 50.5 \\
& Graduate others & 35.4 \\
& Doctorate & 12.1 \\
& & \\
Driving experience & Less than 1 year & 14.1 \\
& 1-5 years & 37.4 \\
& $5-10$ years & 21.2 \\
& $>10$ years & 25.3 \\
\hline
\end{tabular}

\section{$4 \quad$ Results and Discussion}

Most of the respondents were familiar with the autonomous vehicles as shown in the Table 2. The highest $88.9 \%$ respondents had heard about the self-driving vehicles before, while $11.1 \%$ respondents were unaware about it. As the respondents in this study were well educated and mostly (50.5\%) with the technical background of study, therefore it was expected they would be aware about the self-driving vehicles. The awareness level can be further explored particularly focusing on the group of people whose education level is lower than graduation.

Table 2. Awareness about self-driving vehicles

\begin{tabular}{lcc}
\hline & Frequency & Percent \\
No & 11 & 11.1 \\
Yes & 88 & 88.9 \\
Total & 99 & 100.0 \\
\hline
\end{tabular}

Over all $74.7 \%$ respondents expressed their interest to have self-driving vehicle and $25.2 \%$ people were found not to be interested in having autonomous vehicles. It needs further investigation about the concerns of people who are not interested in owning the self-driving vehicle.

Table 3. Level of interest in having a self-driving vehicle 


\begin{tabular}{llcc}
\hline & Frequency & Percent & $\begin{array}{c}\text { Cumulative } \\
\text { Percent }\end{array}$ \\
Very much interested & 32 & 32.3 & 32.3 \\
Interested & 42 & 42.4 & 74.7 \\
Not too much interested & 22 & 22.2 & 97.0 \\
Not interested at all & 3 & 3.0 & 100.0 \\
Total & 99 & 100.0 & \\
\hline
\end{tabular}

When people were asked about the level of automation they wanted to have in their vehicles, about 34\% respondents expressed their interest to have level 3 automation in their vehicles following $26.8 \%$ and $25.8 \%$ to have level 2 and level 4 respectively. It is represented in the Table 4. This depicts the psychology of user's that they want to have some sort of control (level 2 and 3) in their hands rather than totally relying on automation (such as in level 4). Similar kind of results were found in the study conducted in developed countries [13] where people were more concerned about using level 4 as compared to level 3.

Table 4. Level of interest in having different levels of automation

\begin{tabular}{lccc}
\hline & Frequency & Percent & $\begin{array}{c}\text { Cumulative } \\
\text { Percent }\end{array}$ \\
No Automation & 5 & 5.2 & 5.2 \\
Level 1 Automation & 8 & 8.2 & 13.4 \\
Level 2 Automation & 26 & 26.8 & 40.2 \\
Level 3 Automation & 33 & 34.0 & 74.2 \\
Level 4 Automation & 25 & 25.8 & 100.0 \\
Total & 97 & 100.0 & \\
\hline
\end{tabular}

Regarding the reliability of self-driving vehicle technology, $60 \%$ respondents think that this technology would be moderately reliable and $16 \%$ think it would be very reliable. While $13 \%$ people expressed their views as an unreliable technology. The majority of the respondents $(65.7 \%)$ feel it would be safe to ride in the selfdriving vehicles. While $34.4 \%$ people disagree about feeling safe in self-driving vehicles. When people were asked "I may feel unsafe while riding in the self-driving vehicle due to possibility of system failure and collision”. Most of the respondents (73.1\%) considered it unsafe in the case of system failure and accidents.

Table 5. Perception about safety (system failure and collision)

\begin{tabular}{lccc}
\hline & Frequency & Percent & $\begin{array}{c}\text { Cumulative } \\
\text { Percent }\end{array}$ \\
Strongly Disagree & 4 & 4.1 & 4.1 \\
Disagree & 22 & 22.7 & 26.8 \\
Agree & 50 & 51.5 & 78.4 \\
Strongly Agree & 21 & 21.6 & 100.0 \\
Total & 97 & 100.0 & \\
\hline
\end{tabular}


Approximately $70 \%$ people thought they need to monitor the roadway while driving in the self-driving vehicles though $28.3 \%$ disagree with the concept of monitoring while sitting in the self-driving vehicle. Most of the people (59.6\%) expect that the self-driving vehicles will increase the road safety and decrease the road accidents. The higher percentage of respondents $(67.7 \%)$ is of view that self- driving vehicles could improve the traffic movement by minimizing the delays. When people were asked about feeling stressful while dealing with the self-driving technology, 53.6\% people disagree about this feeling. However, $44.5 \%$ respondents express their concern about feeling stressful while interacting with the self-driving vehicles. Most of the people (72.2\%) think the intensive training will be needed to drive the self-driving vehicles.

Table 5. Perception about training requirements

\begin{tabular}{llcc}
\hline & Frequency & Percent & $\begin{array}{c}\text { Cumulative } \\
\text { Percent }\end{array}$ \\
Strongly Disagree & 3 & 3.1 & 3.1 \\
Disagree & 24 & 24.7 & 27.8 \\
Agree & 45 & 46.4 & 74.2 \\
Strongly Agree & 25 & 25.8 & 100.0 \\
Total & 97 & 100.0 & \\
\hline
\end{tabular}

About the decrease in the driver's fatigue and work load, 83.9\% people agree it would happen in the case of self-driving vehicles. While small percentage of respondents (13.1\%) was not agreed with it. Similar kind of result was found when people were asked about the increase in travelling convenience in self-driving vehicles. Mostly (78.8\%) people think it will increase the convenience of travelling. When people were asked about the replacement of human drivers with the self-driving vehicles, interestingly $72.1 \%$ people said that the self-driving vehicles can't replace the human drivers.

Table 6. Replacement of human drivers

\begin{tabular}{lccc}
\hline & Frequency & Percent & $\begin{array}{l}\text { Cumulative } \\
\text { Percent }\end{array}$ \\
Strongly Disagree & 3 & 3.1 & 3.1 \\
Disagree & 24 & 24.7 & 27.8 \\
Agree & 50 & 51.5 & 79.4 \\
Strongly Agree & 20 & 20.6 & 100.0 \\
Total & 97 & 100.0 & \\
\hline
\end{tabular}

Majority of the respondents (61.6\%) will not be comfortable riding a self-driving vehicle while interacting with human driven vehicles on road. The rest of the respondents (36.4\%) think it will be comfortable to come across with conventional vehicles on road. Approximately 84\% respondents think they will be more comfortable riding a self-driving vehicle on highways.

Table 7. Comfort while using self-driving vehicle

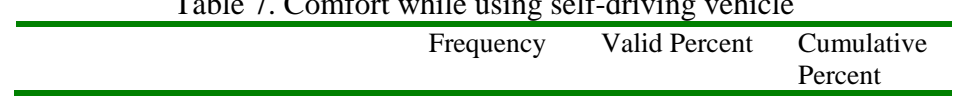




\begin{tabular}{llll}
\hline Strongly Disagree & 1 & 1.0 & 1.0 \\
Disagree & 13 & 13.4 & 14.4 \\
Agree & 58 & 59.8 & 74.2 \\
Strongly Agree & 25 & 25.8 & 100.0 \\
Total & 97 & 100.0 & \\
\hline
\end{tabular}

If the perception about the above factors is compared with the cruise control users, majority of the users of cruise control (77.2\%) feel safe as compared to the non-user of cruise control (65.7\%). In a similar way higher percentage of cruise control users (77.3\%) said they don't feel stressful while using it. Also 90.9\% people said their workload is reduced and $86.3 \%$ found it very convenient to use the cruise system.

Similar kind of opinion was found about the usage of automation for long distances. Overall $86.4 \%$ respondents said they prefer to use cruise control system for long routes and highways.

\section{Conclusion}

Almost everybody has understanding about the latest vehicle technology (selfdriving or autonomous vehicles) and people are interested in opting it. Majority is convinced about the benefits like increase in comfort, safety, convenience and reduction in delays and fatigue. However, training about the use of such system has been taken as the necessary requirement before the actual drive. Similarly, people have fear about the response of system in collision or system failure case. Cruise control users are relatively more satisfied and have more confidence, that can be because of the fact that they are familiar with the use of technology and have positive experience. It suggests that user's knowledge and training about self-driving vehicle system can overcome their concerns and their reliability could also be enhanced once they start using the technology.

\section{References}

1. Richard, W., Silberg, G.: Self-driving cars: the next revolution - KPMG and CAR (Center for Automotive research), http://www.kpmg.com/Ca/en/IssuesAndInsights/ArticlesPublications/Documents/self drivingcars-next-revolution. pdf,(consulted on April 7th 2014) (2012): 2.

2. Richard, W., Silberg, G.: Self-driving cars: the next revolution - KPMG and CAR (Center forAutomotive research), http://www.kpmg.com/Ca/en/IssuesAndInsights/ArticlesPublications/Documents/self drivingcars-next-revolution. pdf,(consulted on April 7th 2014) (2012): 2.

3. O'Toole, R.: Gridlock: Why we're stuck in traffic and what to do about it, Cato Institute (2009)

4. Ibañez-Guzmán, J., Jian, X., Malcolm, A., Gong, Z., Chan, C.W. Tay, A.: Autonomous armoured logistics carrier for natural environments, Intelligent Robots and Systems, (IROS. Proceedings 2004 IEEE/RSJ International Conference on IEEE, pp. 473 (2004) 
5. Le Vine, S., Zolfaghari, A., Polak, J.: Autonomous cars: The tension between occupant experience and intersection capacity. Transportation Research Part C: Emerging Technologies, 52 pp 1--14 (2015).

6. Shladover, S., Ioannou, P.: "Reasons for operating AHS vehicles in platoons", Automated highway systems, pp 11-27 (1997).

7. . Forrest, A., Konca, M.,: Autonomous Cars and Society. Department of Social Science and Policy Studies, Worcester Polytechnic Institute Worcester (2007)

8. Folsom, T. C.: Social Ramifications of Autonomous Urban Land Vehicles, IEEE International Symposium on Technology and Society, Chicago (2011).

9. Cowen, T.: Can I See Your License, Registration and C.P.U.? The New York Time, [online] 28 May (2011), Available at: http://www.nytimes.com/2011/05/29/business/economy/29view.html

10. Wu, C., Zhao, G. Ou, B.: A fuel economy optimization system with applications in vehicles with human drivers and autonomous vehicles, Transportation Research Part D: Transport and Environment, 16(7) pp 515--524 (2011).

11. Stock, K.: Autonomous Driving. Accessed 3rd March (2016) http://citeseerx.ist.psu.edu/viewdoc/download?doi=10.1.1.128.3935\&rep=rep1\&type $=$ pdf

12. McCarthy, N.: Autonomous Systems: Social, Legal and Ethical Issues", Transportation Research Board (2009)

13. Schoettle, B., Sivak, M.: A survey of public opinion about autonomous and selfdriving vehicles in the US, the UK, and Australia (2014). 